\title{
Damping Determination by Half-Power Bandwidth Method for a Slightly Damped Rectangular Steel Plate in the Mid-Frequency Range
}

\author{
M. F. Treszkai ${ }^{1, *}$, D. Sipos ${ }^{1}$, D. Feszty ${ }^{1}$ \\ ${ }^{1}$ Department of Whole Vehicle Development, Audi Hungaria Faculty of \\ Automotive Engineering, Széchenyi István University, 9026, Győr, Hungary \\ *E-mail: treszkai.marcell.ferenc@ga.sze.hu
}

Abstract: This paper presents a novel methodology for measuring the Damping Loss Factor (DLF) of a slightly damped plate in the mid-frequency range (400-1000 Hz) by the Half Power Bandwidth Method (HPBM). A steel flat plate of $650 \times 550 \times 2 \mathrm{~mm}$ was considered as the test case, which was excited by both a shaker and an impact hammer to quantify the effect of the excitation type for slightly damped plate. Since the HPBM is based on extracting the damping data from the modal resonance peaks, working with the correct Frequency Response Functions (FRF) was found to be a crucial factor. Therefore, the effects of coherence and resolution of the sampling frequency were examined in detail in the measurements. The obtained DLF results were statistically analysed and then applied in SEA simulations. Comparison of the simulation and experimental results showed that the method of extracting the DLF data from the measurements can have as much as $10 \mathrm{~dB}$ influence on the simulation results. The best results, with only 2 $\mathrm{dB}$ difference between measurement and simulation, were obtained when the statistical expected value of the data was used as the input in the SEA simulations.

Keywords: vibroacoustic measurements; damping loss factor; DLF; Statistical Energy Analysis

\section{Introduction}

In Noise, Vibration and Harshness ( $\mathrm{NVH}$ ) analyses, the accurate determination of damping is one of the most critical tasks, since it serves as an input parameter to 
vibroacoustic simulations, let them be either of Finite Element Method (FEM) or Statistical Energy Analysis (SEA) type. Thus, the precision of the damping data applied can compromise the accuracy of the simulation results. In general, damping is characterised by the Damping Loss Factor (DLF), which can be determined either from the database of the actual simulation software, experimentally from measurements or from look up tables. The most accurate way to evaluate the DLF for a given structure is to calculate it from measurements.

In Statistical Energy Analysis simulations, DLF is an especially important input parameter, since the response results depend directly on the damping value. Eq. 1 shows the basic formulation of the Power Injection Method (PIM), which is the foundation for SEA simulation methods. According to this, the power injection for an individual subsystem is the following [1]:

$$
\Pi_{\text {in }}=\omega E \eta,
$$

where $\Pi_{\text {in }}$ is the power, which is injected into the subsystem, $\omega$ is the angular frequency, $E$ is the kinetic energy of the subsystem, and $\eta$ is the Damping Loss Factor of the subsystem. This highlights, that the value of DLF is crucial from simulation accuracy point of view for SEA.

Table 1. shows an overview of the literature, related to determining the damping parameters for simplified systems or plates. As one can see from it, there have been numerous papers published on the experimental determination of Damping Loss Factor, but the measurement methods used were quite diverse. Beyond this, only a few papers comment on the statistical distribution of the DLF values or investigate the effect of the experimental results in simulations. In addition, none of the papers makes a correlation between the way how the boundary conditions are realized or their effect on DLF. In summary, no prior literature has investigated the following parameters simultaneously: 1) the correlation between the measurement boundary conditions and the change of DLFs, 2) the statistics of the damping values, 3) comparison of simulation and experimental results.

Therefore, the aim of this paper is to formulate guidelines for the determination of the damping for an extremely sensitive, slightly damped steel plate in the midfrequency region $(400-1000 \mathrm{~Hz}$ ) with simultaneous consideration of the effect of the realisation of the boundary conditions, the statistics of the measured date and a comparison between SEA simulations and experiments. The paper starts with examining the most important parameters for correct shaker excitation as well as its limitations. Comparison to impact hammer excitation is provided too. In this paper, damping is determined via the Half-Power Bandwidth Method, while the uncertainty of the DLF values will be statistically evaluated and applied in SEA simulations. Finally, comparison of the simulations and experiments is provided. 
Table 1. Review of the literature related to damping determination via experiments.

\begin{tabular}{|c|c|c|c|c|c|}
\hline Paper & $\begin{array}{l}\text { Examined } \\
\text { structure }\end{array}$ & $\begin{array}{c}\text { DLF } \\
\text { determination } \\
\text { method } \\
\end{array}$ & $\begin{array}{c}\text { DLF } \\
\text { statistics }\end{array}$ & $\begin{array}{l}\text { Measurement } \\
\text { sensitivity study }\end{array}$ & $\begin{array}{c}\text { SEA } \\
\text { simulation } \\
\text { comparison }\end{array}$ \\
\hline $\begin{array}{c}\text { J. Petrik, } \\
\text { et al., } 2016 \text { [2] }\end{array}$ & $\begin{array}{l}\text { Plywood } \\
\text { plate }\end{array}$ & $\begin{array}{c}\text { Impact test, } \\
\text { DRM }\end{array}$ & Yes & No & No \\
\hline $\begin{array}{c}\text { M. } \\
\text { Bustamante, et } \\
\text { al., 2016 [3] }\end{array}$ & $\begin{array}{c}\text { Steel, } \\
\text { Aluminum } \\
\text { plate, Beam }\end{array}$ & $\begin{array}{l}\text { Shaker test, } \\
\text { HPBM, PIM }\end{array}$ & Yes & Yes & No \\
\hline $\begin{array}{l}\text { M.B. Mandale, } \\
\text { et al., } 2015 \text { [4] }\end{array}$ & $\begin{array}{l}\text { Metal and } \\
\text { Composite } \\
\text { plates }\end{array}$ & $\begin{array}{l}\text { Impact test, } \\
\text { HPBM }\end{array}$ & No & No & No \\
\hline $\begin{array}{l}\text { A.A. Jadhav, } \\
\text { et al., } 2015 \text { [5] }\end{array}$ & Glass plate & $\begin{array}{c}\text { Impact test, } \\
\text { HPBM }\end{array}$ & No & Yes & No \\
\hline $\begin{array}{l}\text { R. Cherif, et } \\
\text { al., } 2015 \text { [6] }\end{array}$ & $\begin{array}{l}\text { Aluminum } \\
\text { and } \\
\text { composite } \\
\text { plates }\end{array}$ & $\begin{array}{l}\text { Shaker test, } \\
\text { LDV; PIM, } \\
\text { HPBM, DRM, } \\
\text { IWCM }\end{array}$ & No & Yes & No \\
\hline $\begin{array}{l}\text { M. Jaber, et } \\
\text { al., } 2014 \text { [7] }\end{array}$ & $\begin{array}{l}\text { Composite } \\
\text { plate }\end{array}$ & $\begin{array}{c}\text { Shaker test, } \\
\text { Laser } \\
\text { Vibrometer; } \\
\text { PIM, HPBM } \\
\end{array}$ & Yes & Yes & No \\
\hline $\begin{array}{l}\text { L. Zoghaib, et } \\
\text { al., } 2013 \text { [8] }\end{array}$ & $\begin{array}{l}\text { Aluminum } \\
\text { plate }\end{array}$ & $\begin{array}{c}\text { Acoustic } \\
\text { excitation, Laser } \\
\text { Vibrometer; } \\
\text { DRM } \\
\end{array}$ & Yes & Yes & No \\
\hline $\begin{array}{l}\text { N. Schiller, et } \\
\text { al., } 2010 \text { [9] }\end{array}$ & $\begin{array}{l}\text { Composite } \\
\text { cylinder }\end{array}$ & $\begin{array}{c}\text { Shaker test, } \\
\text { Laser } \\
\text { Vibrometer; } \\
\text { DRM } \\
\end{array}$ & Yes & No & Yes \\
\hline $\begin{array}{l}\text { R. Cabell, et } \\
\text { al., } 2009 \text { [10] }\end{array}$ & $\begin{array}{l}\text { Curved, } \\
\text { stiffened } \\
\text { sidewall } \\
\end{array}$ & $\begin{array}{c}\text { PIM, Manual } \\
\text { DRM, } \\
\text { Automated DRM } \\
\end{array}$ & Yes & No & No \\
\hline $\begin{array}{c}\text { N.K. Mandal, } \\
\text { et al., } 2004 \\
{[11]} \\
\end{array}$ & $\begin{array}{c}\text { Steel plates, } \\
\text { damping } \\
\text { layers } \\
\end{array}$ & $\begin{array}{c}\text { Shaker test, } \\
\text { accelerometer } \\
\text { HPBM } \\
\end{array}$ & No & No & No \\
\hline $\begin{array}{c}\text { M. Iwaniec, } \\
2003 \text { [12] }\end{array}$ & $\begin{array}{c}\text { Loudspeaker } \\
\text { shaker test; } \\
\text { DRM } \\
\end{array}$ & $\begin{array}{l}\text { Loudspeaker, } \\
\text { shaker test; DRM }\end{array}$ & Yes & Yes & No \\
\hline $\begin{array}{l}\text { P.R.Mantena, } \\
1996 \text { [13] }\end{array}$ & $\begin{array}{l}\text { Polyester, } \\
\text { Epoxy, } \\
\text { Aluminum, } \\
\text { Graphite } \\
\end{array}$ & $\begin{array}{l}\text { Impact test, Eddy } \\
\text { current probe; } \\
\text { HPBM }\end{array}$ & No & No & No \\
\hline
\end{tabular}




\section{Damping determination from measurement}

There are several methods to determine the DLF experimentally, from which the three most commonly used ones are: the Power Injection Method (PIM), the Decay Rate Method (DRM), and the Half Power Bandwidth Method (HPBM) [2] [7].

The Power Injection Method is based on the Statistical Energy Analysis's powerbalance equations. According to the definition, the DLF is equal to the ratio of the input power and of the product of the total energy of the subsystem and angular frequency. Rearranging eq. (1) allows to express the DLF as:

$$
\eta=\frac{\Pi_{\text {in }}}{\omega E},
$$

This method requires the input power identification during the measurement, thus the input force and the input velocity, must be simultaneously measured. For shaker excitation the usage of an impedance head is required, while for impact excitation an accelerometer close to the hammering point is necessary. To identify the total energy of the subsystem, one must consider several spatial averagings over randomly located response points on the structure. This method is less accurate for low frequencies, and not suitable for extremely lowly damped systems [1] [14].

The second method is the Half Power Bandwidth Method, in which the DLFs are determined from the resonance peaks of the individual modes. It is related to the modal behaviour of the structure. In order to reduce the experimental error during the estimation of the DLF, the averaging over several excitation and response points is required. This method uses the Frequency Response Function (FRF) directly to calculate the $3 \mathrm{~dB}$ drops from the resonance peaks, as shown in Fig. 1. [15] [16].

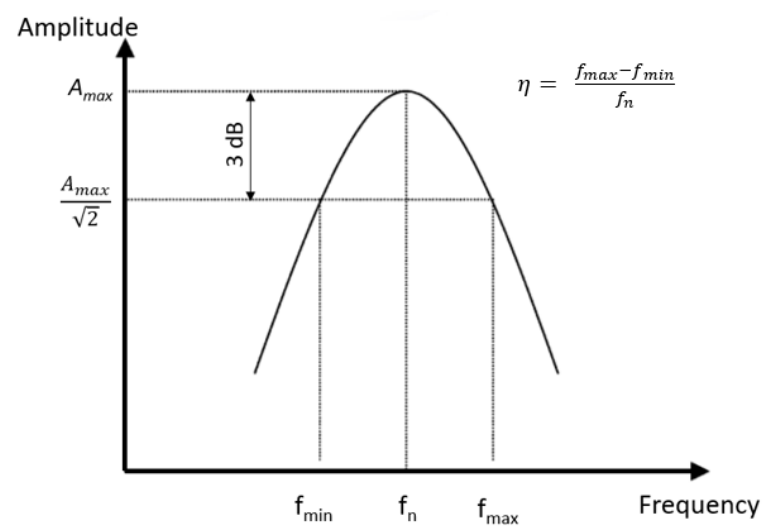

Figure 1. DLF determination from half-power bandwidth from the resonance peak. 
Since this method is based on the individual peaks, the modal density must be taken into account. If this is too high, the peaks coincide and make impossible the use of this method [6]. Eq. (3) provides a guideline for choosing gives the $\Delta f$ that represents the minimum distance of the two modes next to each other [1]:

$$
\Delta f<3 \eta f,
$$

If the modes are too close to each other, one should determine the DLF in another way, such as the third method, the Decay Rate Method (DRM). This is based on evaluating measurement data in the time domain. In general, the excitation comes from impulse source, and the resultant slope of the decay measured in $\mathrm{dB} / \mathrm{s}$ - is termed the Decay Rate (DR) [5]. Fig. 2. illustrates the measurement grapically.

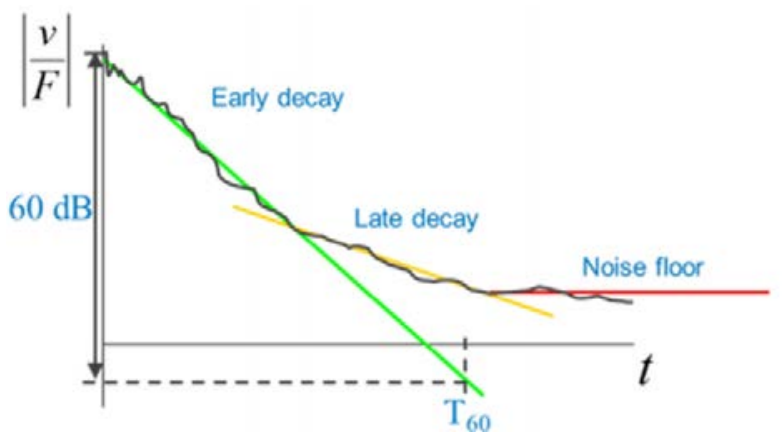

Figure 2. Theoretical background of the Decay Rate Method [2].

The damping loss factor from the decay rate will then be the following [6]:

$$
\eta=\frac{D R}{27.3 f},
$$

Several excitation and response points should be applied over the structure, to get the spatial average over different mode shapes. The DRM is suitable for lightly damped structures, with $\eta<0.1$ [2].

\section{Measurement}

In this section the shaker and impact measurement set-ups will be introduced. The considered test case was a rectangular plate with the size of $650 \times 550 \times 2 \mathrm{~mm}$. Theoretically, all modes should be excited to get the correct DLF of a structure. For this reason, 16 response points were used per excitation point. However, in order to avoid too much added mass to the plate, only 4 accelerometers were used per measurement at any given time [17], thus one excitation point was measured four times. In all measurements, three different excitation points were used to get a large 
number of DLF samples and thus to reduce the experimental error [1]. Free-free boundary conditions were applied, and to ensure these, the plate was hanged on a bungee cord with silicone inserts. The investigated frequency range was the midfrequency range ( $400 \mathrm{~Hz}-1 \mathrm{kHz}$ ), since a) it is a challenging, yet interesting range for many industrial sectors to capture and b) the SEA simulation method itself does not work below this range due to its nature [18].

The source of the excitations were: a) electromagnetic shaker, with a periodic chirp signal and b) impact hammer. Fig. 3. represents the schematic diagram of the measurement setups.
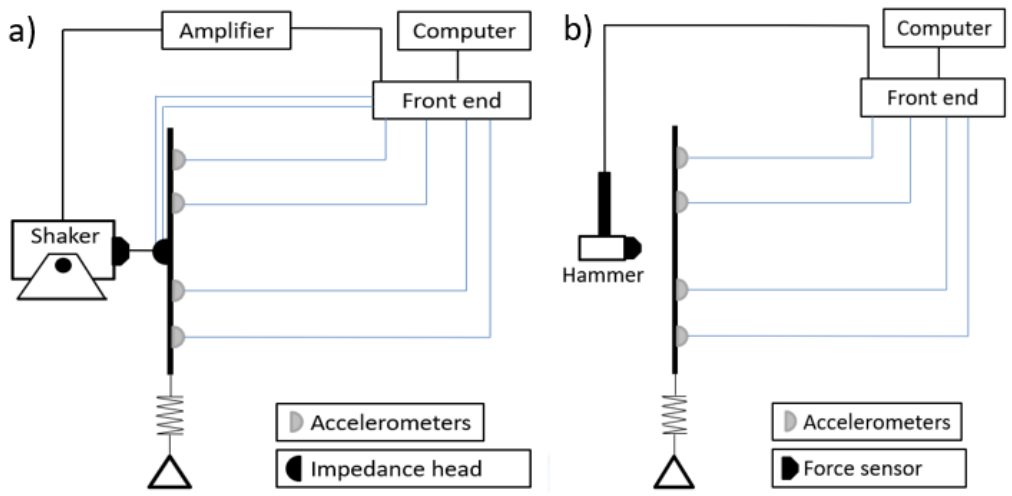

Figure 3. Schematic diagram of the measurement system: a) shaker testing, b) impact testing.

The measurement was performed with the Siemens LMS measurement system. The response was measured by lightweight ICP accelerometer sensors (piezoelectric, B\&K, Type 4519-003) weighing 1.5 grams each. The impedance head was PCB Piezotronics, Type 3321. The impact hammer was PCB Piezotronics (Model Number: 086C03) with hard rubber head.

The shaker excitation range was between $282-1280 \mathrm{~Hz}$. The frequency resolution of the measurement was $0.039 \mathrm{~Hz}$, and Hamming windowing technique was applied [16]. In the impact measurement case, the pre-trigger time was adjusted to about $0.02 \mathrm{sec}$, while the trigger force was $20 \mathrm{~N}$. The impact force spectrum was capable up to $1.8 \mathrm{kHz}$.

\subsection{Shaker testing}

The Half-Power Bandwidth Method was used to determine the DLF values. Since, this method is based on the Frequency Response Function, every factor influencing 
the FRFs can also influence the DLF values. Thus, in this subsection, the parameters influencing the FRF's will be introduced.

\subsubsection{Coherence}

The coherence basically shows that how much of the output signal comes from the input signal, i. e. the presence of any other disturbing signals. These other signals can be for example the consequence of poor hanging conditions, noise in the system or resonances. The definition of the coherence is [15] [19]:

$$
\gamma_{x y}^{2}(f)=\frac{\left|G_{x y}(f)\right|}{G_{x x}(f) G_{y y}(f)},
$$

where $x$ is the signal at the input, $y$ is the signal at the output, $G_{x x}(f)$ is the autospectrum of $x, G_{y y}(f)$ is the auto-spectrum of $y$, and the $G_{x y}(f)$ is the cross-spectrum of the $x$ and $y$ signals [15]. Therefore, the perfect relationship between input and output would give the coherence value of 1 . The coherence must be reasonable in order to get clear FRF curves, so if the signal is too noisy then the FRF would be inaccurate to identify the proper DLF values.

The flexible suspension in not enough to get a good coherence curve, because of the metal-metal friction between the hook and the washer. In order to eliminate this phenomenon, silicone inserts were used (Fig. 4.), which had a quite significant impact on the coherence curves as illustrated in Fig. 5.

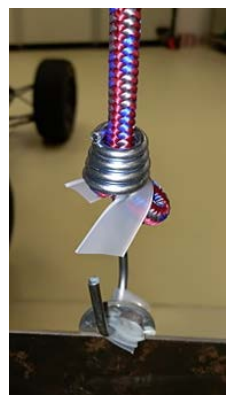

Figure 4. Silicone insert was used between the hook and washer to avoid the metalmetal friction. 


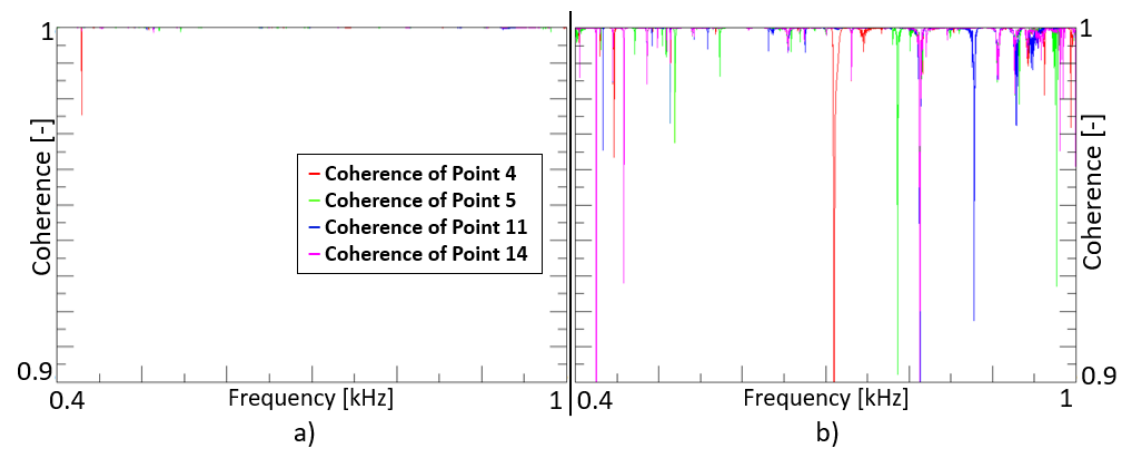

Figure 5. Coherence curves of the same measurement points a) with the silicone inserts $\boldsymbol{b})$ without the silicone insert.

Although, this structure is a linear system, under a certain excitation force, the input signal can become too low compared to the noise level. This can also cause a problem at the output side, because the responses can be out of the sensitivity range of the accelerometers. This should be taken into consideration when conducting measurements, because this can have significant effect on the FRF curve, as shown in Fig. 6.

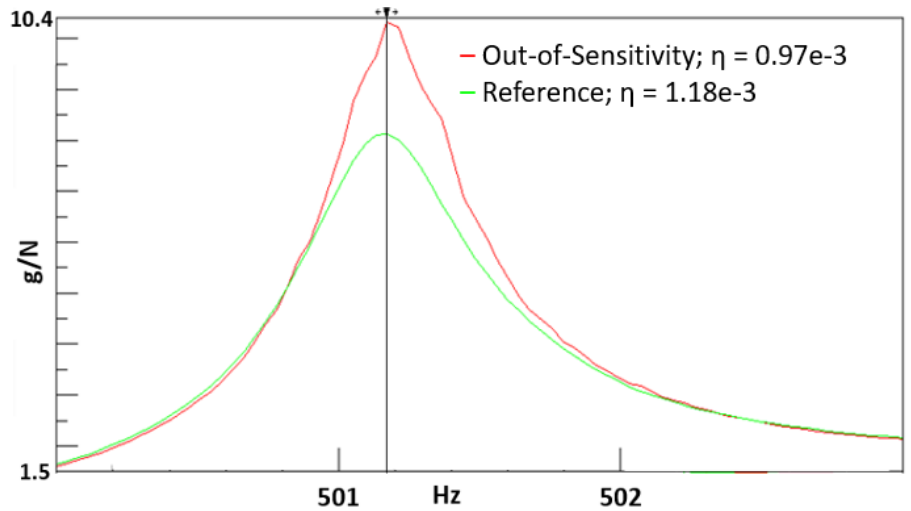

Figure 6. Effect of sensor sensitivity on the DLF values at $501.17 \mathrm{~Hz}$. Green curve: reference measurement with appropriate excitation force. Red curve: low input force, the sensor sensitivity is out of its sensitivity range. Top right shows the DLF values, the difference is $18 \%$.

As Fig. 6. shows, the amplitude of the resonance peaks is overestimated if the input force is smaller than the ideal one from the accelerometer sensitivity point of 
view. The red curve contains more noise than the green one, moreover its damping value has also changed.

\subsubsection{Effect of sampling frequency resolution}

The resolution of the resonance peak is a key factor in order to get smooth response curves and accurate damping values. In order to determine the proper DLF value, with the Half Power Bandwidth Method the frequency resolution must be appropriate. According to Lyon et al. [1] the following equation can be used to determine the required sample points:

$$
N>\frac{20}{\eta}
$$

where $N$ is the number of the sample points per channel, and $\eta$ is the DLF value. During the measurements, most of the DLF values were around $\eta=0.0008$, which requires at least 25,000 sample points, while in the fine measurement case 32,000 spectral lines were used. The problem is that it is difficult to know a-priori the expected DLF value, so it might be required to perform a preliminary-measurement to check the Nyquist circle. If the frequency resolution is not satisfactory, the Nyquist-circle will be angular instead of circular. The aim would be to get a perfectly rounded circle. In the fine case, the frequency resolution was well-resolved, with $0.039 \mathrm{~Hz}$. As a comparison, a coarse resolution case was applied with an order of magnitude larger frequency resolution i.e. $0.39 \mathrm{~Hz}$. Fig. 7. shows the Nyquist diagram of the FRFs for the fine and coarse frequency resolutions at a resonance peak around $501 \mathrm{~Hz}$.

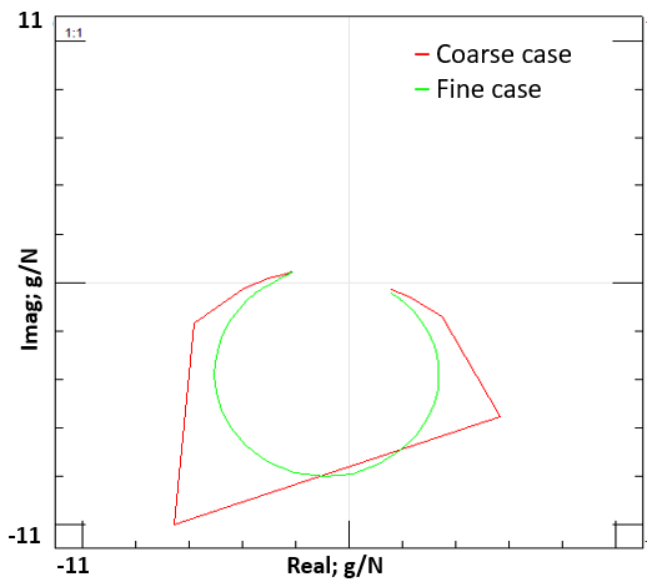

Figure 7. Nyquist diagram for one resonance peak at $501 \mathrm{~Hz}$. Green curve is the fine resolution $(0.039 \mathrm{~Hz})$, red curve is the coarse frequency resolution $(0.39 \mathrm{~Hz})$. 
The same resonance peaks are visualized in Fig. 8. in an Amplitude-Frequency diagram with DLF values at $501 \mathrm{~Hz}$. As one can see, the frequency of the peak is shifted, and the amplitude of the peak is also changed by the frequency resolution. Consequently, the DLF value also changed, when the frequency resolution was coarse.

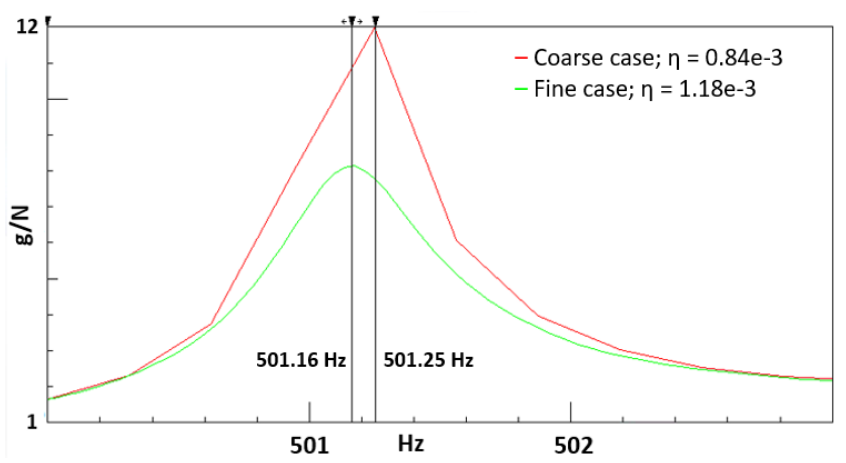

Figure 8. FRF curves with the DLF values around $501 \mathrm{~Hz}$. Green curve represents the reference case with fine frequency resolution $(0.039 \mathrm{~Hz})$, while the red curve the coarse frequency resolution $(0.39 \mathrm{~Hz})$. Top right corner shows the DLF values. The peak of the green curve has at $501.16 \mathrm{~Hz}$ while the red curve has at $501.25 \mathrm{~Hz}$.

Although during the shaker test every important parameter was taken into consideration, the connection of the shaker gave too much additional damping to the system. To avoid this phenomenon, impact testing was tested. At lower frequencies, this effect is not too conspicuous but over $500 \mathrm{~Hz}$ the amplitude of the resonance peaks was changed and shifted, as depicted in Fig. 9.

As the results indicate, the impact excitation allows to realize the free-free boundary condition better than the shaker test since the latter one added additional stiffness and damping to the system. 


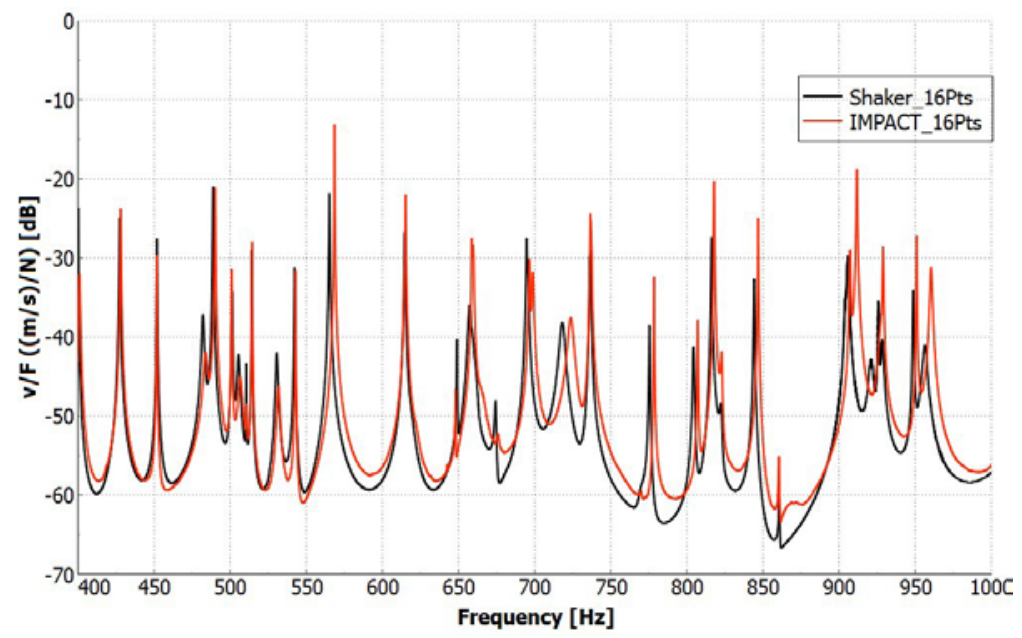

Figure 9. RMS average of 16 response points for shaker and impact excitation cases. The excitation point and the response points were at the same locations for both cases.

\subsection{Impact testing}

During the impact test, all parameter setups, the boundary conditions as well as the excitation and response points were the same as in the shaker excitation case. The only difference was the way of the excitation.

Note that the impact is generated manually by a human and thus the position of the hitting points will never be exactly the same during the four averaging. Hence, the coherence of the impact tests will never be as clear as for the shaker cases, and thus the coherence curves contain lot of collapses as illustrated in Fig. 10.

One consequence of the imperfect coherence curves is that the FRF curves are not as smooth as it was for the shaker excitation case. This can be seen in Fig. 11., which shows the resonance peak at around $501 \mathrm{~Hz}$ for the impact hammer excitation case and at around $502 \mathrm{~Hz}$ at the shaker excitation case. 
M.F. Treszkai et al. - Acta Technica Jaurinensis, Vol. 13, No. 3, pp. 177-196, 2020

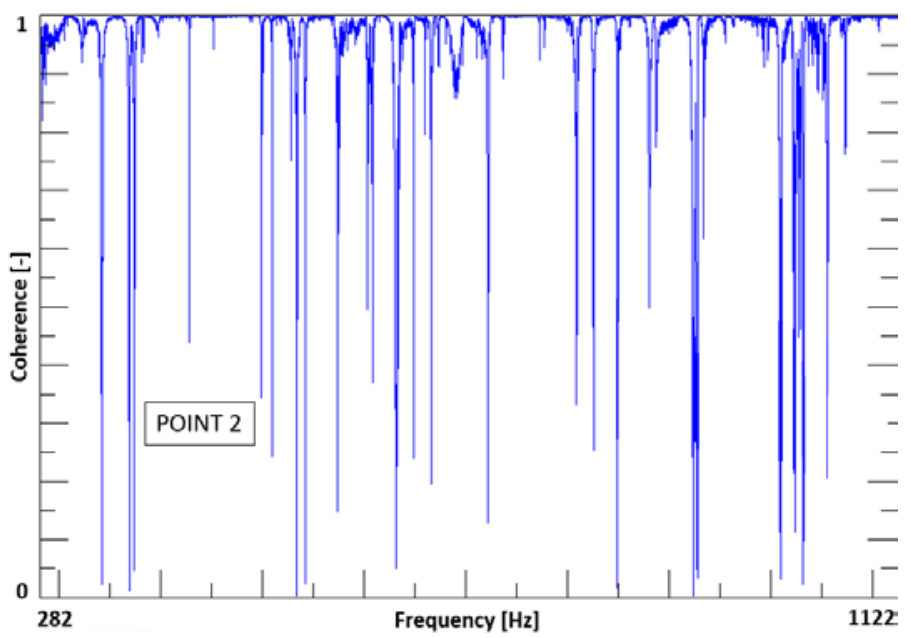

Figure 10. Coherence curve from impact excitation at Response Point 2.

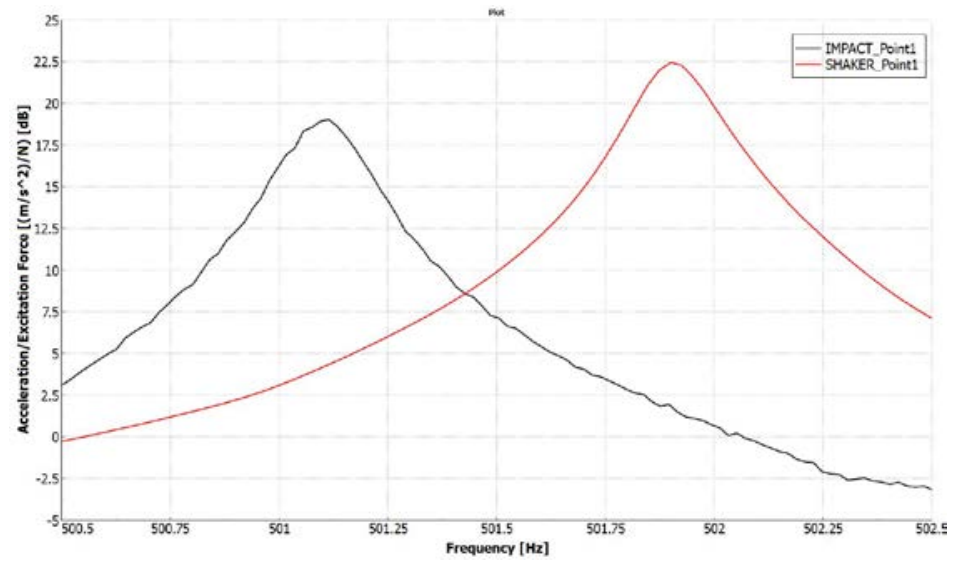

Figure 11. FRF curve of the impact hammer and shaker excitation cases in Point 1.

\subsubsection{Statistics of DLF values}

The investigated frequency range was in the mid-frequency range, i.e. between 355 to $1122 \mathrm{~Hz}$. These are the lower and upper borders of the investigated third octave bands. In this area the shaker connection had a great influence on the results and for this reason only the impact hammer DLF results were investigated and compared to the simulation results. 
However, note that according to equation (3), the modal overlapping over a certain frequency makes this method unsuitable. Interestingly, although the structure exhibited some close peaks in the last third octave band (891 - $1122 \mathrm{~Hz}$ ), the method appeared to remain still valid for this plate. The highest frequency in the last band is $1122 \mathrm{~Hz}$, and the average damping value in this band was $\eta \sim 9.6 \mathrm{e}-4$. Thus, in this case the $\Delta f$ should be around 3.3 Hz. Note that there were some peaks close to each other, the two closest ones can be seen in Fig. 12. All others had a larger distance between them than the minimum required $\Delta f$.

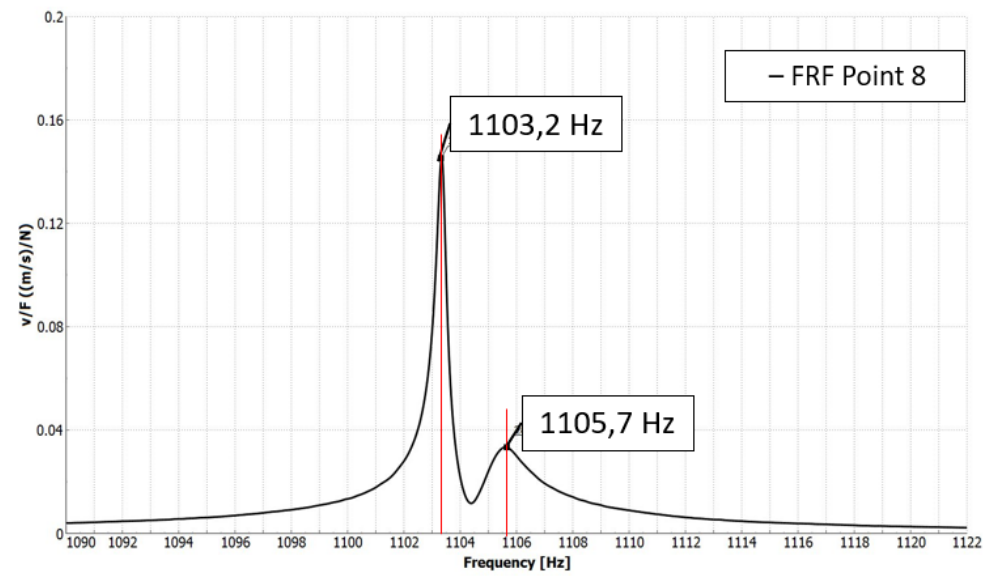

Figure 12. The closest peaks at the last third octave band. The $\Delta$ f between the neighbouring peaks is $2.5 \mathrm{~Hz}$, while the ideal should be $3.2 \mathrm{~Hz}$.

Recall, that three different excitation points and 16 response points were used, so in total 48 FRF curves were investigated. From these curves the DLF values were calculated for each frequency band. Fig. 13. shows the average DLF values in every third octave band, for the three load cases, along with deviations. 


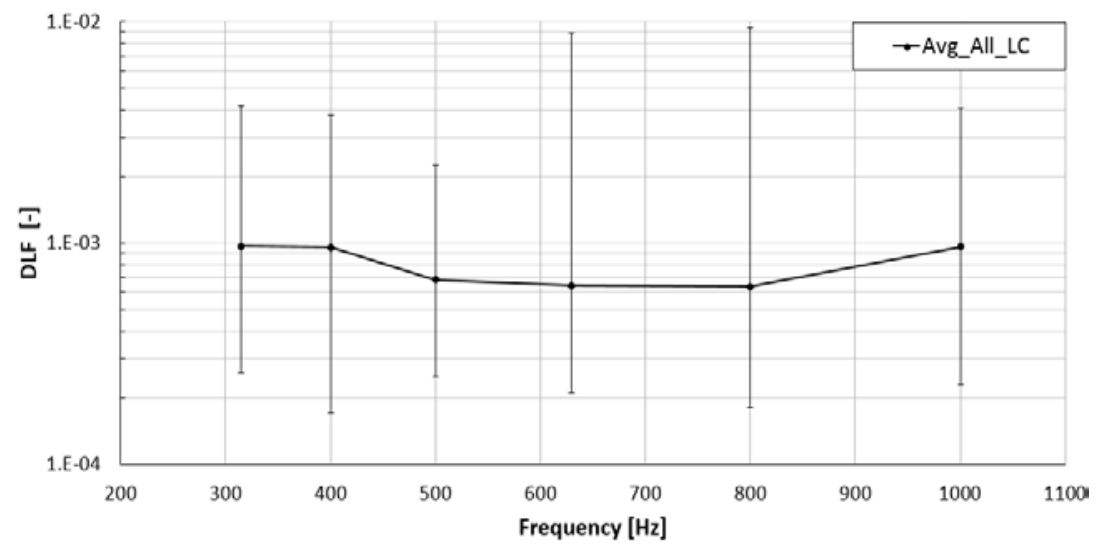

Figure 13. Average of the DLFs with deviations. Note that 16 response points were considered for each excitation, in all 3 impact positions.

The number of the samples is clearly sufficient to characterize the given frequency band. Note that the $400 \mathrm{~Hz}$ third octave band included the smallest number of samples, but still with as much as 130 datasets. In order to evaluate such large dataset, a statistical approach was used. The distribution of the data was investigated by plotting the histograms of each third octave bands. The Kolmogorov-Smirnov (K-S) goodness test of fitting data to theoretical distribution was performed. The histograms showed that the samples were skewed, thus lognormal distribution was assumed in the K-S test. The statistics calculated can be expressed as [9]:

$$
D_{n}=\sup \left|F_{n}(x)-\phi(x)\right| ;-\infty<x<\infty,
$$

In case of $D_{n} \geq D_{\text {crit }}$, the null hypothesis can be rejected. The K-S test of fitting the data to the theoretical distribution showed that the null hypothesis - stating that the data shown by Fig. 14. come from a lognormal distribution - cannot be rejected at 95\% significance level [2]. 


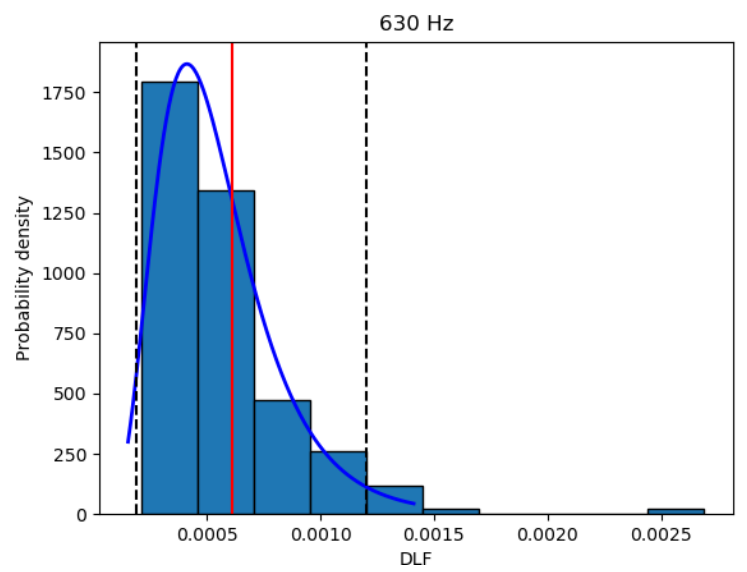

Figure 14. Histogram of samples at $630 \mathrm{~Hz}$ third octave band, probability density function of the fitted lognormal distribution (blue line), expected value (red line) and the 95\% confidence intervals (black dashed lines) of the fitted distribution function.

The histogram of the other third octave bands showed similar trends. Thus, the confidence intervals and the expected values were calculated from the fitted lognormal distributions.

\section{DLF values application in Statistical Energy Analysis simulation}

In essence, SEA is a high frequency method, which assumes high modal density. In this work the mid-frequency range $(355-1122 \mathrm{~Hz})$ was considered for the analysis. Although, the method is generally suitable for flat plates, the particular structure examined in this paper was not the most ideal SEA subsystem, since it had quite low modal density in the mid-frequency range [20].

Simulations were run by the ESI VA One software. During the simulations, a $1 \mathrm{~N}$ point force was applied as the excitation. Every important parameter, such as the sizes, the mass and the material, were the same as for the real structure. The simulation was run with the expected DLF values from the log-normal distribution from the Half Power Bandwidth Method. The measurement curve was obtained from the RMS average of all response curves. The third octave band averages of the curves were considered. Fig. 15. shows the simulation results compared to the experiment. 
M.F. Treszkai et al. - Acta Technica Jaurinensis, Vol. 13, No. 3, pp. 177-196, 2020

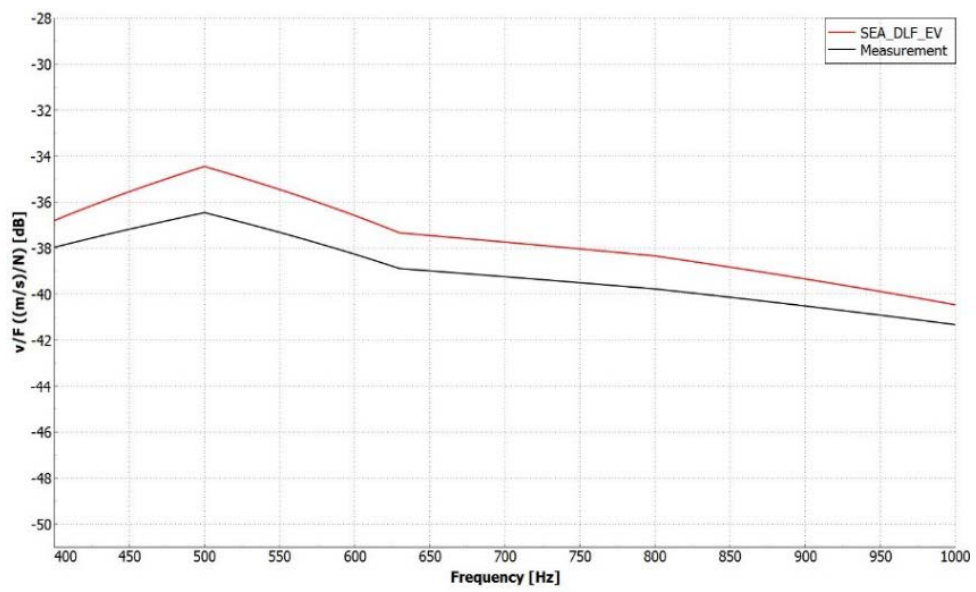

Figure 15. Comparison of the velocity/force results for the simulation and experiment results. DLF values are the expected value of the log-normal distribution.

The simulation results showed good agreement with the measurements. The maximum difference was around $2 \mathrm{~dB}$ at $500 \mathrm{~Hz}$. In order to illustrate the uncertainty of the DLF values, the maximum and minimum values were taken in all third octave bands and compared to the experiment, as shown in Fig. 16.

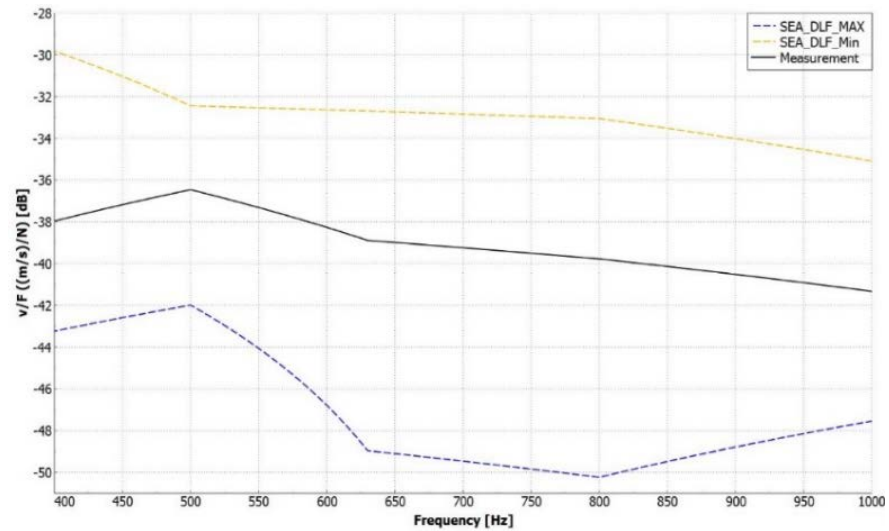

Figure 16. Comparison of the velocity/force results for the measurement and simulation with applying the extreme values of the DLFs from the measurement data in Fig.13. 
As one can see, using the minimum and maximum extremes of the DLF can highly influence the results. The difference between the two extremes can be very large, for example about as much as $17 \mathrm{~dB}$ at $800 \mathrm{~Hz}$. Since the DLF values follow log-normal distribution, the maximum and minimum values of the $95 \%$ confidence level were also taken and compared to the experiment, as shown in Fig. 17.

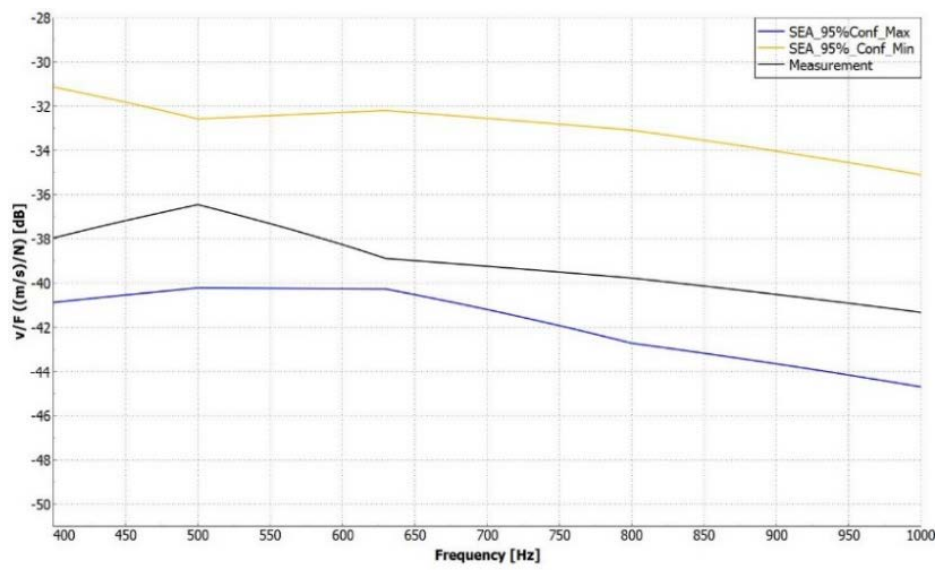

Figure 17. Comparison of the velocity/force results for the measurement and simulation with applying the 95\% confidence intervals of the DLFs from the measurement data as shown in Fig. 14.

As one can see the difference can be still significant, with the maximum deviation around $11 \mathrm{~dB}$ at $800 \mathrm{~Hz}$.

\section{Conclusions}

As the examples showed, the value of measured DLF is highly influenced by the quality of the FRFs. All the parameters must be taken into account (e.g. coherences, frequency resolution, etc.) in order to achieve proper damping results, especially for such an extremely lightly damped plate, which was examined in this paper. Small changes in the setup can cause large differences in the damping. Therefore, it is recommended to ensure that the right ratio of the excitation force compared to the noise level is applied as well as that the frequency resolution of the setup is sufficiently fine. After the first measurement, one needs to check the results, from frequency resolution, and coherence point of view, because these parameters can affect the DLF significantly. The shaker excitation ensures nearly perfect coherence curves and smooth FRFs, but its connection could add damping, mass and stiffness to the system. On the other hand, the hammer excitation is free of these effect, but 
inherently lead to less coherent FRFs than for the shaker case. Consequently, for a slightly damped plate the impact hammer excitation could be a better solution, if it is feasible. The capability of the Half Power Bandwidth Method is based on the individual resonance peaks. For this reason, the modal overlapping must be checked at higher frequencies. If the peaks are too close to each other, the method is unable to determine the Damping Loss Factor, and another damping determination method must be found. The DLF determination by HPBM required huge amount of work to calculate the damping from each individual peak, but as the results show, when the method is combined with the statistical analysis of a large number of samples, it is capable to obtain good results for a very sensitive structure. Future work should involve examining the applicability of these guidelines to more complex structures involving various damping materials.

\section{Acknowledgement}

This work was supported by the Hungarian Academy of Sciences and Audi Hungaria Zrt. through the MTA-SZE Lendület Vehicle Acoustics Research Group and also through the "Internationalisation, initiatives to establish a new source of researchers and graduates and development of knowledge and technological transfer as instruments of intelligent specialisations at Széchenyi István University" (EFOP3.6.1-16-2016-00017).

\section{References}

[1] R. H. Lyon, R. G. DeJong, Theory and Application of Statistical Energy Analysis, $2^{\text {nd }}$ Edition, Butterworth-Heinemann, Oxford, 1995.

[2] J. Petrik, R. Fiedler, P. Lepsík, Loss factor estimation of the plywood materials, JVE International LTD. Vibroengineering Procedia 7 (2015) pp. 1554-1563.

[3] M. Bustamante, S. N. Y. Gerges, E. F. Vergara, J. P. Arenas, High Damping Characteristics of an Elastomer Particle Damper, International Journal of Acoustics and Vibration 21 (1) (2016) pp. 112-121. doi: https ://dx.doi.org/10.20855/ijav.2016.21.1401

[4] M. B. Mandale, P. Bangarubabu, S. M. Sawant, Damping Loss Factor Estimation by Experimental Method for Plate with Conventional and Composite Materials, International Journal on Design \& Manufacturing Technologies 9 (2) (2015) pp. 6-13. doi: http://dx.doi.org/10.18000/ijodam. 70152 
[5] A. A. Jadhav, S. R. Desai, Estimation of Damping Loss Factor (DLF) for Automotive Glass, Journal of Basic and Applied Engineering Research 2 (6) (2015) pp. 435-438.

[6] R. Cherif, J-D. Chazot, N. Atalla, Damping Loss Factor Estimation of TwoDimensional Orthotropic Structures from a Displacement Field Measurement, Journal of Sound Vibration 356 (2015) pp. 61-71.

doi: https://doi.org/10.1016/j.jsv.2015.06.042

[7] M. Jaber, H. Schneeweiss, J. Bös, T. Melz, Measurement of the Damping Properties of Carbon Composite Plates by the Power Input Method, Proceedings of ISMA2014 Including USD2014, EMVeM, 2014 pp. 14451458.

[8] L. Zoghaib, P-O. Mattei, Damping Analysis of a Free Aluminum Plate, Journal of Vibration and Control 21 (11) (2015) pp. 2083-2089.

doi: $h$ ttps ://doi .org/10.1177/1077546313507098

[9] N. Schiller, R. Cabell, F. Grosveld, Impact of Damping Uncertainty on SEA Model Response Variance, Noise-Con 2010, Baltimore, Maryland, 2010. April 19-21.

[10] R. Cabell, N. Schiller, A. Allen, M. Moeller, Loss Factor Estimation Using the Impulse Response Decay Method on a Stiffened Structure, Inter-Noise 2009, Ottawa, Canada, 2009. August 23-26.

[11] N. K. Mandal, R. A. Rahman, M. S. Leong, Experimental Study on Loss Factor for Corrugated Plates by Bandwidth Method, Ocean Engineering (31) (2004) pp. 1313-1323.

doi: https://doi.org//10.1016/j.oceaneng.2003.08.003

[12] M. Iwaniec, Damping Loss Factor Estimation in Plates, Molecular and Quantum Acoustics (24) (2003) pp. 61-68.

[13] P. R. Mantena, Frequency-Domain Vibration Analysis for Characterizing the Dynamic Mechanical Properties of Materials, 1996 ASEE Annual Conference Proceedings, Session 1626, 1996. 
[14] S. A. Hambric, S. H. Sung, D. J. Nefske, Engineering vibroacoustic analysis, Methods and Applications, John Wiley \& Sons, Ltd., Chichester, West Sussex, United Kingdom, 2016.

[15] Siemens LMS Help guide, 2019.

[16] The Fundamentals of Modal Testing, Application Note 243-3 Agilent Technologies, 2000.

[17] N. H. Baharin, R. A. Rahman, Effect of accelerometer mass on thin plate vibration, Jurnal Mekanikal, (29) (2009) pp. 100-111.

[18] W. Desmet, B. Pluymers,O. Atak, "MID-FREQUENCY" - CAE Methodologies for Mid-Frequency Analysis in Vibration and Acoustics, Katholieke Universiteit Leuven - Faculty of Engineering, (2012) pp. 233-262.

[19] A. Grzadziela, M. Kluczyk, Application of coherence functions of vibroacoustic signals from piston engines, recorded in set states, for their technical evaluation, Journal of Polish CIMAP 7 (2) (2012) pp. 55-64.

[20] MECAS ESI Group, VA One Users’ Guide, 2018. 